\title{
A presença da tecnologia na Educação do Campo: mapeamento da produção científica nacional dos últimos cinco anos
}

\author{
Vagner Viera de Souza ${ }^{1}$, Elaine Corrêa Pereira ${ }^{2}$, Celiane Costa Machado ${ }^{3}$ \\ ${ }^{1}$ Universidade Federal do Rio Grande - FURG. Programa de Pós Graduação em Educação em Ciências: \\ Química da Vida e Saúde. Avenida Itália, Km 8. Campus Carreiros. Rio Grande - RS. \\ Brasil. vagner@vagnersouza.com. ${ }^{2}$ Universidade Federal do Rio Grande - FURG. ${ }^{3}$ Universidade Federal do Rio \\ Grande - FURG
}

\begin{abstract}
RESUMO. Este artigo tem por objetivo realizar um mapeamento das produções científicas brasileiras, dentro da biblioteca digital do SciELO, as quais abordem as temáticas Tecnologia e Educação do Campo. Com a finalidade de visualizar o cenário nacional atual em relação às publicações relacionadas à tecnologia nas escolas do campo, buscamos por trabalhos em língua portuguesa com as seguintes palavraschave: Tecnologia na Educação, Educação do Campo e Tecnologia da Educação do Campo. Em posse dos resultados, realizamos uma análise comparativa entre a produção total recuperada e a produção do período de 2013 a 2017. Assim, podemos identificar em quais campos as pesquisas estão mais avançadas em relação às publicações e, onde encontramos menos resultados, como em relação à Tecnologia e Educação do Campo, o que pode vir a atrair novas pesquisas e publicações nestas áreas menos exploradas.
\end{abstract}

Palavras chave: Mapeamento, Produção Científica, Tecnologia, Educação do Campo. 


\title{
The presence of technology in Rural Education: mapping of national scientific production of the last five years
}

\begin{abstract}
The objective of this article is to map the Brazilian academic productions, within the SciELO digital library, which will address the topics of Technology and Education in the rural areas. In order to visualize the current national scenario in relation to the publications related to technology in the rural schools, we search for Portugueselanguage works with the following keywords: Technology in Education, Rural Education and Rural Education Technology. With the results, we performed a comparative analysis between the total production recovered and production from the period from 2013 to 2017. Thus, we can identify in which fields of study the searches are more advanced in relation to the publications and, where we find less results, such as those refer to Technology and Rural Education, which may attract new research and publications in these less-exploited areas.
\end{abstract}

Keywords: Mapping, Academic Production, Technology, Rural Education. 


\section{La presencia de la tecnología en la Educación del campo: mapa de la producción científica nacional de los últimos cinco años}

RESUMEN. Este artículo tiene por objetivo realizar un mapeamiento de las producciones académicas brasileñas, dentro de la biblioteca digital del SciELO, las cuales aborden las temáticas Tecnología y Educación del Campo. Con el fin de ver la escena nacional actual en relación a las publicaciones relacionadas con la tecnología en las escuelas del campo, buscamos trabajar en idioma portugués con las siguientes palabras clave: Tecnología en la Educación, Educación Rural y Tecnología Educación Rural. En posesión de los resultados, realizamos un análisis comparativo entre la producción total recuperada y la producción del período de 2013 a 2017. Así, podemos identificar en qué campos las encuestas están más avanzadas en relación a las publicaciones y, donde encontramos menos resultados, como las que se refiere a la Tecnología y la Educación del Campo, lo que puede atraer nuevas investigaciones y publicaciones en estas áreas menos explotadas.

Palabras clave: Mapeo, Producción Académica, Tecnología, Educación del Campo. 


\section{Introdução}

A educação é essencial no que tange o desenvolvimento social do sujeito. A partir disto, podemos trazer a escola como principal provedora de conhecimento e educação, a qual promove aos seus estudantes meios para que se tornem não apenas cidadãos, mas sujeitos conscientes do seu papel na sociedade em que vivem. A escola é importante, mas não é o único caminho. Segundo Libâneo (2007, p. 25), “a escola não é mais a única agência de transmissão do saber, na verdade ela nunca deteve sozinha este papel". Neste mesmo sentido, Saviani (2005) diz que a escola é uma instituição que tem seu papel centrado na socialização do saber sistematizado e que existe para propiciar a aquisição dos instrumentos que possibilitam o acesso ao saber elaborado (ciência), bem como o próprio acesso aos rudimentos deste saber.

Mesmo existindo outros meios, alheios à escola, onde o ser humano pode ter acesso a novos conhecimentos, não podemos negar o importante papel desenvolvido pela escola enquanto instituição de ensino, tanto nas zonas rurais quanto nas zonas urbanas. A educação nas áreas rurais é uma temática que vem fortalecendo-se ao longo dos anos.

Conforme Carlos (2007, p. 131), em um "âmbito que vai para além do que é urbano ou do que é rural", pois longe de serem meras palavras são conceitos que reproduzem uma realidade social concreta. A autora complementa que "a cidade e o campo se diferenciam pelo conteúdo das relações sociais neles contidas e estas, hoje, ganham conteúdo em sua articulação com a construção da sociedade urbana".

Quando referimo-nos à educação, mais especificamente nos tempos atuais, é preciso destacar a presença da tecnologia. Este tema está interligado ao nosso cotidiano, estando presente em quase todas as atividades diárias. Indiferentemente de onde estamos, a tecnologia está próxima a nós. Kenski (2015, p. 23) cita que "tecnologia é poder", e este conceito vai muito além do senso comum. A autora diz que "... o conceito de tecnologia engloba a totalidade de coisas que a engenhosidade do cérebro humano conseguiu criar em todas as épocas, suas formas de uso, suas aplicações". Significa que este conceito é muito mais amplo do que costumamos pensar e abrange muito mais do que apenas "máquinas".

A tecnologia é essencial para a educação, ao mesmo tempo em que ambas não são indissociáveis. Segundo o dicionário Ferreira (1999), a educação diz respeito ao "processo de desenvolvimento da capacidade física, intelectual e moral da criança e do ser humano em geral, visando à sua melhor integração individual e social”. Em consonância, Kenski (2015) 
afirma que para ocorrer essa integração é necessário que valores, conhecimentos, hábitos e comportamentos sociais sejam ensinados e aprendidos, por meio da educação, para ensinar sobre as tecnologias na base da identidade e da ação do grupo e que se faça uso destas mesmas tecnologias para ensinar as bases da educação.

A partir disto, podemos destacar a relevância que a tecnologia tem na educação e nos questionamos sobre a sua contribuição ao ensino, quando o assunto são as escolas do campo. Pesquisas sobre esta temática vêm sendo desenvolvidas atualmente. Compreendendo a tecnologia como temática importante para a educação contemporânea, realizamos um mapeamento das produções científicas brasileiras, dentro da Scientific Electronic Library Online (SciELO), as quais abordem as temáticas "Tecnologia" e “Educação do Campo".

\section{Sobre a importância da pesquisa científica}

Desde que a humanidade deixou de ser nômade, a territorialidade passou a ser permeada por disputas e conflitos. A má distribuição de terras é historicamente conhecida e acaba por beneficiar a poucos. Estes, por sua vez, possuem vastas extensões de terras, o que promove que detenham o poder.
Ainda hoje, estas terras que por muitas vezes são improdutivas ou destinadas ao agronegócio, são o divisor de águas entre a riqueza de quem explora o meio ambiente e o trabalhador do campo e a pobreza de quem nem ao menos possui um pedaço de chão para viver. Uma pequena área de campo, onde se possa tirar o sustento de sua família, é um privilégio para poucos. O pequeno agricultor que planta e colhe para a sua subsistência é o principal afetado pelo modelo agroindustrial imposto, que se fortalece a cada dia.

Pesquisar meios para melhorar a vida de quem vive no campo é essencial nos dias de hoje, mesmo com a diminuição do êxodo rural que, segundo o Censo Demográfico 2010 do Instituto Brasileiro de Geografia e Estatística (IBGE, 2010), caiu pela metade quando comparado com a década anterior. É preciso qualificar a vida de quem ainda está nas zonas rurais e promover meios para que estes sujeitos, assim como as suas famílias, possam continuar no campo tendo uma vida digna.

A escola é uma grande parceira no que diz respeito à promoção de direitos. É preciso salientar que, para isto, faz-se necessário o entendimento das peculiaridades das pessoas e do contexto onde a escola está inserida. É comum vermos nos livros didáticos e nas situações hipotéticas utilizadas para abstrair as 
atividades escolares, símbolos que muitas vezes não fazem sentido para os estudantes do campo. Não pelo fato de desconhecimento, mas pela ausência de simbologia e relação com o seu cotidiano. Quando se fala, por exemplo, em placas de trânsito, largas avenidas ou congestionamento, situações essas que não fazem parte da vida de quem vive no campo, ocorre uma quebra na linha de raciocínio.

A reflexão sobre o trabalho que uma determinada escola pretende fazer está diretamente ligada ao seu contexto e ao perfil dos seus estudantes. Diante disto, surge a urgência da pesquisa sobre esta temática, a problematização da docência no ensino das pessoas que vivem no campo, levando em consideração artefatos pertencentes ao meio urbano, mas que também são encontrados no meio rural. Os artefatos promovem, de acordo com Fischer (2006, p. 15), “envolvimento com a produção e circulação de significados e sentidos, os quais, por sua vez, estão relacionados a modos de ser, a modos de pensar, a modos de conhecer o mundo, de se relacionar com a vida".

Realizar uma pesquisa bibliográfica, muitas vezes, não é uma tarefa simples. Existem diversas fontes de informação e nem todas são de acesso aberto e gratuito. $\mathrm{O}$ acesso à informação é algo relevante a ser discutido, principalmente para as pessoas que desenvolvem pesquisas. A busca errada, não confiável e disseminada, pode acarretar problemas para $\mathrm{O}$ desenvolvimento e conclusão de muitos trabalhos.

Antes da era da informática um artigo acadêmico era indexado a uma fonte de informação, gerando um alto custo e dificilmente atingia o público ao qual foi destinado. Segundo Goldenberg, Castro e Azevedo (2007, p. 92), “antes do advento da internet, um artigo chegava a seu leitor por estar indexado, em uma importante fonte de informação. Desse modo, um círculo vicioso se fechava, pois os artigos publicados fora deste circuito dificilmente atingiam seu público”.

Por sua vez, com o desenvolvimento das tecnologias, principalmente as voltadas à informação, houve uma diminuição de custos, facilidade no acesso e a possibilidade maior de publicação das pesquisas realizadas. Logo,

O desenvolvimento das tecnologias da informação tem diminuído as dificuldades enfrentadas pelos editores com poucos recursos. O custo de produção e distribuição dos periódicos foi substancialmente reduzido com os métodos de publicações eletrônicas. E a indexação dos artigos, outro ponto nevrálgico do processo, passou a ser feito pelos chamados motores de busca na internet ... Assim, bons artigos passaram a ter chance de serem reconhecidos por suas 
qualidades (Goldenberg, Castro \& Azevedo, 2007, p. 93).

Por outro lado, inicia-se a discussão sobre a qualidade das informações. A mesma ferramenta que possibilita a publicação de bons artigos, com pesquisas e resultados, pode, em contrapartida, viabilizar que outros trabalhos com inferior ou quase nenhuma qualidade também sejam publicados. Para isso, surgem critérios e avaliações, restringindo a quantidade e buscando maior qualidade da informação.

Os critérios visam organizar o processo de seleção, objetivando o alcance da coerência, adequação e legitimidade das fontes e recursos de informação. Segundo Vergueiro (2010), alguns dos critérios são a precisão, imparcialidade, cobertura ou tratamento, relevância, atualidade ou valor histórico e qualidade do trabalho científico. Isto se atinge através das chamadas avaliações por pares.

Para encontrar exatamente aquilo que procuramos, é necessário refinar os resultados das buscas, de acordo com os objetivos pretendidos na pesquisa. Para este refinamento, é possível utilizar filtros a fim de criar delimitações que, por sua vez, restringem os resultados recuperados. Desta maneira, no momento da pesquisa nas fontes de informação também é possível utilizar-se de operadores booleanos como "AND", "OR" e "NOT", com a finalidade de especificar melhor os termos buscados.

Em relação a esta pesquisa podemos dizer que optamos por esta área devido ao nosso entendimento sobre a importância da produção científica para alavancar, através das suas publicações, melhorias significativas no paradigma atual em que nos encontramos, enquanto sociedade.

\section{Sobre a pesquisa e o mapeamento}

A investigação realizada foi de cunho quantitativo, com o objetivo de realizar um mapeamento das produções científicas brasileiras, da biblioteca digital do SciELO, as quais abordam a temática da Tecnologia e da Educação do Campo. Uma pesquisa quantitativa, que tem suas raízes no pensamento positivista lógico, tende a enfatizar o raciocínio dedutivo, as regras da lógica e os atributos mensuráveis da experiência humana. Por sua vez, a pesquisa qualitativa tende "a salientar os aspectos dinâmicos, holísticos e individuais da experiência humana, para apreender a totalidade no contexto daqueles que estão vivenciando o fenômeno", conforme citam Polit, Becker e Hungler (2011, p. 201). Neste mesmo sentido, Fonseca (2002, p. 20) diz que:

Diferentemente da pesquisa qualitativa, os resultados da pesquisa quantitativa podem ser quantificados. Como as amostras geralmente são 


\begin{abstract}
grandes e consideradas representativas da população, os resultados são tomados como se constituíssem um retrato real de toda a população alvo da pesquisa. A pesquisa quantitativa se centra na objetividade. Influenciada pelo positivismo, considera que a realidade só pode ser compreendida com base na análise de dados brutos, recolhidos com o auxílio de instrumentos padronizados e neutros. A pesquisa quantitativa recorre à linguagem matemática para descrever as causas de um fenômeno, as relações entre variáveis, etc. A utilização conjunta da pesquisa qualitativa e quantitativa permite recolher mais informações do que se poderia conseguir isoladamente.
\end{abstract}

A diferença entre pesquisas quantitativas e qualitativas não é de oposição, mas de ênfase, o que não implica exclusividade (Minayo, 2012). Nesta linha de pensamento podemos observar a este respeito três considerações importantes:

1) Não há nenhum método melhor do que o outro, o método, "caminho do pensamento", ou seja, o bom método será sempre aquele capaz de conduzir o investigador a alcançar as respostas para as suas perguntas, ou dizendo de outra forma, a desenvolver seu objeto, explicá-lo ou compreendê-lo, dependendo de sua proposta (adequação do método ao problema de pesquisa); 2) Os números (uma das formas explicativas da realidade) são uma linguagem, assim como as categorias empíricas na abordagem qualitativa o são e cada abordagem pode ter seu espaço específico e adequado; 3) Entendendo que a questão central da cientificidade de cada uma delas é de outra ordem ... a qualidade, tanto quantitativa quanto qualitativa depende da pertinência, relevância e uso adequado de todos os instrumentos (Minayo \& MinayoGómez, 2003, p. 118).

Segundo Gil (2017, p. 41), de acordo com os seus objetivos, a pesquisa poderá:

... adotar o perfil exploratório, o que irá proporcionar proximidade com a problemática. O que, por sua vez, pode envolver levantamento bibliográfico, entrevistas com pessoas que tiveram experiências com o problema pesquisado ou análise de exemplos que estimulem a compreensão.

Desta maneira, tanto a pesquisa quantitativa quanto a pesquisa qualitativa apresentam diferenças com pontos fracos e fortes. Mesmo assim, os elementos fortes de um complementam as fraquezas do outro, fundamentais ao maior desenvolvimento da Ciência.

\section{Metodologia aplicada na pesquisa}

Para a realização do mapeamento sobre o cenário atual da produção científica com a temática Tecnologia na Educação do Campo, utilizamos três termos como palavras-chave: Tecnologia na Educação, Educação do Campo e Tecnologia na Educação do Campo. Partindo destas palavras-chave, a pesquisa foi realizada na biblioteca digital do SciELO. A escolha por esta fonte se deu mediante os seus critérios de avaliação, indexação e permanência dos periódicos. Além disso, é uma plataforma de acesso 
aberto, a qual contribui para o aumento da visibilidade, qualidade e credibilidade das produções nacionais e internacionais.

Primeiramente, foram realizadas buscas em todos os índices, a fim de obter um panorama geral sobre o número de artigos que resultariam nesta etapa. Neste momento não foram utilizadas delimitações, como pode ser observado na Tabela 1.

Tabela 1. Resultados referentes à primeira busca.

\begin{tabular}{|c|c|}
\hline Termo pesquisado & Resultados \\
\hline Tecnologia na Educação & 786 \\
\hline Educação do Campo & 2616 \\
\hline $\begin{array}{c}\text { Tecnologia na Educação do } \\
\text { Campo }\end{array}$ & 91 \\
\hline
\end{tabular}

Fonte: Pesquisa dos Autores (2018).

Dando continuidade ao trabalho, foi necessário utilizar o índice "resumo" a fim de delimitar a busca em trabalhos que tivessem maior relação com os termos procurados. Logo, pesquisando por este índice, as palavras-chave estariam compondo o tex to de resumo dos trabalhos. $\mathrm{O}$ primeiro termo a ser pesquisado foi Tecnologia na Educação, o qual resultou em 292 resultados. Para refinar estes resultados com o objetivo de qualificar o retorno dos dados, foram aplicados alguns filtros para delimitar estes números.

$\mathrm{Na}$ Tabela 2, podemos acompanhar o resultado obtido da pesquisa, pela palavrachave Tecnologia na Educação, sem a utilização de filtros, logo em seguida delimitando os resultados pelo país "Brasil" e, por fim, filtrando pelo idioma "português".

Tabela 2. Resultados da busca geral e com a aplicação de filtros.

\begin{tabular}{|c|c|c|}
\hline $\begin{array}{c}\text { Termo } \\
\text { pesquisado }\end{array}$ & $\begin{array}{c}\text { Filtro(s) } \\
\text { aplicado(s) }\end{array}$ & Resultados \\
\hline $\begin{array}{c}\text { Tecnologia na } \\
\text { Educação }\end{array}$ & - & 292 \\
\hline $\begin{array}{c}\text { Tecnologia na } \\
\text { Educação }\end{array}$ & Brasil & 199 \\
\hline $\begin{array}{c}\text { Tecnologia na } \\
\text { Educação }\end{array}$ & $\begin{array}{c}\text { Brasil / Idioma } \\
\text { Português }\end{array}$ \\
\hline
\end{tabular}

Fonte: Pesquisa dos Autores (2018).

Com os dados apresentados na Tabela 2, podemos observar que, quando o resultado é filtrado por país, obtemos uma mudança considerável nos números. Eles diminuem de 292 para 199 com a utilização deste filtro, que é essencial devido ao nosso objetivo de mapear a produção brasileira. $\mathrm{Na}$ continuação do refinamento dos dados inserimos um novo delimitador, desta vez em relação ao idioma das publicações, com intuito de visualizar a produção brasileira apenas em nosso idioma.

Ao filtrar os resultados da pesquisa pelo idioma "português", observamos uma diminuição de aproximadamente $40 \%$ (quarenta por cento) no número de artigos recuperados nesta pesquisa, quando comparados à busca filtrada apenas pelo 
país "Brasil", a qual diminuía em torno de $32 \%$ (trinta e dois por cento). Esta diferença demonstra que os brasileiros não produzem apenas em língua portuguesa e ressalta a importância de refinar a busca entre país e idioma, quando pretendemos encontrar determinados resultados, baseados nos dados que objetivamos analisar. De maneira geral, podemos ressaltar a importância da seleção dos dados recuperados, visto que, para obtenção de resultados válidos para a pesquisa pretendida, é necessário o tratamento destes dados.

É interessante destacar que, se comparadas as produções resultantes da pesquisa (Tabela 3), desde a data inicial de recuperação (período 1998- 2017) com os resultados obtidos na delimitação deste trabalho, que se referem ao período 2013 2017, encontramos uma diferença de 96 (noventa e seis) artigos. Ou seja, quase $50 \%$ (cinquenta por cento) da produção científica brasileira, em língua portuguesa, relacionada com a temática Tecnologia na Educação foi publicada nos últimos cinco anos.

Tabela 3. Quantidade total de trabalhos encontrados no período $1998-2017$.

\begin{tabular}{|c|c|c|}
\hline $\begin{array}{c}\text { Termo } \\
\text { pesquisado }\end{array}$ & Período & $\begin{array}{c}\text { Total de } \\
\text { trabalhos } \\
\text { recuperados }\end{array}$ \\
\hline $\begin{array}{c}\text { Tecnologia na } \\
\text { Educação }\end{array}$ & $1998-$ & 178 \\
\hline Tecnologia na & 2017 & 82 \\
Educação & 2017 & \\
\hline
\end{tabular}

Com a intenção de visualizar o panorama atual da produção científica brasileira, consideramos apenas os dados resultantes da pesquisa, filtrados pelos últimos 5 (cinco) anos. Na Tabela 4, podemos acompanhar o número de publicações relacionadas com a temática Tecnologia na Educação, filtradas no período de 2013 a 2017.

Tabela 4. Resultados do período 2013 a 2017 , apresentados ano a ano.

\begin{tabular}{|c|c|c|}
\hline $\begin{array}{c}\text { Termo } \\
\text { pesquisado }\end{array}$ & $\begin{array}{c}\text { Ano de } \\
\text { publicação }\end{array}$ & Resultados \\
\hline $\begin{array}{c}\text { Tecnologia na } \\
\text { Educação }\end{array}$ & 2013 & 17 \\
\hline $\begin{array}{c}\text { Tecnologia na } \\
\text { Educação }\end{array}$ & 2014 & 16 \\
\hline $\begin{array}{c}\text { Tecnologia na } \\
\text { Educação }\end{array}$ & 2015 & 19 \\
\hline $\begin{array}{c}\text { Tecnologia na } \\
\text { Educação }\end{array}$ & 2016 & 17 \\
\hline $\begin{array}{c}\text { Tecnologia na } \\
\text { Educação }\end{array}$ & 2017 & \\
\hline
\end{tabular}

Fonte: Pesquisa dos Autores (2018).

Como podemos acompanhar na Tabela 4, a quantidade de trabalhos relacionados com a temática variam, não permitindo estabelecer uma linha crescente ou decrescente de produções.

Voltando a pesquisa para a segunda palavra-chave, obtemos resultados diferentes. Quando pesquisamos por Educação do Campo, pelo índice resumo, o resultado apresentado é 1547 publicações. Neste resultado, aplicamos os filtros país

Fonte: Pesquisa dos Autores (2018). 
"Brasil" e idioma "português", conforme a

Tabela 5, apresentada a seguir.

Tabela 5. Resultados da busca geral e com a aplicação de filtros.

\begin{tabular}{|c|c|c|}
\hline $\begin{array}{c}\text { Termo } \\
\text { pesquisado }\end{array}$ & $\begin{array}{c}\text { Filtro(s) } \\
\text { aplicado(s) }\end{array}$ & Resultados \\
\hline $\begin{array}{c}\text { Educação do } \\
\text { Campo }\end{array}$ & - & 1547 \\
\hline $\begin{array}{c}\text { Educação do } \\
\text { Campo }\end{array}$ & Brasil & 1165 \\
\hline $\begin{array}{c}\text { Educação do } \\
\text { Campo }\end{array}$ & $\begin{array}{c}\text { Brasil/Idioma } \\
\text { Português }\end{array}$ & 1121 \\
\hline
\end{tabular}

Fonte: Pesquisa dos Autores (2018).

A partir dos resultados desta pesquisa podemos refletir sobre a importância de pesquisar e levar efetivamente a discussão sobre a tecnologia para as escolas, em especial, as que se localizam no campo. Este fato pode mobilizar ações inovadoras em salas de aula, difundindo o conhecimento de forma ampla e eficaz, o que poder servir para diminuir as diferenças sociais, no que tange a promoção do acesso à informação.

Ainda sobre a análise dos dados, podemos notar mais uma vez a diferença entre o número de publicações quando filtradas por país "Brasil" e o número de publicações filtradas por país "Brasil" somado ao filtro idioma "português". Nesta situação, os números diminuem em aproximadamente $25 \%$ (vinte e cinco por cento) e $28 \%$ (vinte e oito por cento), respectivamente. Em contraponto aos dados da Tabela 2 que, quando aplicados os mesmos filtros, apresentam uma diminuição aproximada de $32 \%$ (trinta e dois por cento) e $40 \%$ (quarenta por cento).

Quando comparamos o total da produção recuperada nesta pesquisa relacionada à temática Educação do Campo no período 2013 - 2017 com o total geral de resultados obtidos (Tabela 6), podemos observar que mais de um terço dos artigos encontrados foram publicados nos últimos cinco anos. Isso demonstra um significativo aumento da produção científica nesta área do saber.

Tabela 6. Quantidade total de trabalhos encontrados e nos últimos cinco anos.

\begin{tabular}{|c|c|c|}
\hline $\begin{array}{c}\text { Termo } \\
\text { pesquisado }\end{array}$ & Período & $\begin{array}{c}\text { Total de } \\
\text { trabalhos } \\
\text { recuperados }\end{array}$ \\
\hline $\begin{array}{c}\text { Educação do } \\
\text { Campo }\end{array}$ & $\begin{array}{c}1971- \\
2017\end{array}$ \\
\hline $\begin{array}{c}\text { Educação do } \\
\text { Campo }\end{array}$ & $2013-$ & 514 \\
\hline
\end{tabular}

Fonte: Pesquisa dos Autores (2018).

Ao separar os resultados da pesquisa por ano de publicação (Tabela 7), podemos observar que não existe uma grande diferença no número de publicações quando comparadas ano a ano, assim como também acontece na Tabela 3. Continuamos a observar que a quantidade de publicações referente à temática Educação do Campo é constante, mesmo na visualização ano a ano é mais expressiva quando comparada aos 
resultados encontrados com a palavrachave anterior.

Tabela 7. Resultados do período 2013 a 2017.

\begin{tabular}{|c|c|c|}
\hline $\begin{array}{c}\text { Termo } \\
\text { pesquisado }\end{array}$ & $\begin{array}{c}\text { Ano de } \\
\text { publicação }\end{array}$ & Resultados \\
\hline $\begin{array}{c}\text { Educação do } \\
\text { Campo }\end{array}$ & 2013 & 107 \\
\hline $\begin{array}{c}\text { Educação do } \\
\text { Campo }\end{array}$ & 2014 & 94 \\
\hline $\begin{array}{c}\text { Educação do } \\
\text { Campo }\end{array}$ & 2015 & 98 \\
\hline $\begin{array}{c}\text { Educação do } \\
\text { Campo }\end{array}$ & 2016 & 108 \\
\hline $\begin{array}{c}\text { Educação do } \\
\text { Campo }\end{array}$ & 2017 & \\
\hline
\end{tabular}

Fonte: Pesquisa dos Autores (2018).

Quando optamos por mesclar as duas temáticas buscando pela palavra-chave Tecnologia na Educação do Campo, os números obtidos são bem diferentes. No momento em que delimitamos a busca, passando a pesquisar pelas palavras-chave no resumo dos artigos, este resultado cai para 51 (cinquenta e um) trabalhos recuperados. Os números do resultado da busca diminuem à medida que vamos aplicando os filtros país "Brasil" e idioma "português", conforme apresentado na Tabela 8.

Tabela 8. Resultados da busca geral e com a aplicação de filtros.

\begin{tabular}{|c|c|c|}
\hline Termo pesquisado & $\begin{array}{c}\text { Filtro } \\
\text { aplicado }\end{array}$ & Resultados \\
\hline $\begin{array}{c}\text { Tecnologia na } \\
\text { Educação do Campo }\end{array}$ & - & 51 \\
\hline $\begin{array}{c}\text { Tecnologia na } \\
\text { Educação do Campo }\end{array}$ & Brasil & 33 \\
\hline $\begin{array}{c}\text { Tecnologia na } \\
\text { Educação do Campo }\end{array}$ & $\begin{array}{c}\text { Brasil / Idioma } \\
\text { Português }\end{array}$ & 28 \\
\hline
\end{tabular}

Fonte: Pesquisa dos Autores (2018).
À medida que delimitamos a busca através dos filtros, menores foram os números de artigos encontrados, ao mesmo tempo em que melhor nos direcionamos a um resultado de acordo com o foco da pesquisa. Isto se deve ao fato de que diversos artigos que aparecem na recuperação da busca não necessariamente estão relacionados com a temática a ser analisada. Muitos trabalhos apenas citam alguns dos termos pesquisados, não os tendo como objeto de estudo.

Na Tabela 9, estão os números totais referentes às pesquisas no período dos últimos cinco anos e desde o primeiro resultado recuperado até 2017.

Tabela 9. Quantidade total de trabalhos encontrados e nos últimos cinco anos.

\begin{tabular}{|c|c|c|}
\hline Termo pesquisado & Período & $\begin{array}{c}\text { Total de } \\
\text { trabalhos } \\
\text { recuperados }\end{array}$ \\
\hline Tecnologia na & $2009-$ & 28 \\
Educação do Campo & 2017 & 15 \\
\hline Tecnologia na & $2013-$ & \\
Educação do Campo & 2017 & \\
\hline
\end{tabular}

Fonte: Pesquisa dos Autores (2018).

Com estes dados podemos observar que o resultado mais antigo com a temática da Tecnologia da Educação do Campo, nas bases do SciELO, é datado no ano de 2009. Também é possível visualizar que a produção referente ao período de 2013 a 2017 é responsável por mais da metade da produção total encontrada.

$\mathrm{Na}$ Tabela 10, podemos visualizar os resultados da pesquisa pelo termo 
Tecnologia na Educação do Campo ano a ano, no período de 2013 a 2017.

Tabela 10. Resultados do período 2013 a 2017.

\begin{tabular}{|c|c|c|}
\hline Termo pesquisado & $\begin{array}{c}\text { Ano de } \\
\text { publicação }\end{array}$ & Resultados \\
\hline $\begin{array}{c}\text { Tecnologia na } \\
\text { Educação do } \\
\text { Campo }\end{array}$ & 2013 & 03 \\
\hline $\begin{array}{c}\text { Tecnologia na } \\
\text { Educação do } \\
\text { Campo }\end{array}$ & 2014 & 02 \\
\hline $\begin{array}{c}\text { Tecnologia na } \\
\text { Educação do } \\
\text { Campo }\end{array}$ & 2015 & 03 \\
\hline $\begin{array}{c}\text { Tecnologia na } \\
\text { Educação do } \\
\text { Campo }\end{array}$ & 2016 & 03 \\
\hline $\begin{array}{c}\text { Tecnologia na } \\
\text { Educação do } \\
\text { Campo }\end{array}$ & 2017 & 04 \\
\hline \multicolumn{2}{|c|}{ Fonte: Pesquisat } & \\
\hline
\end{tabular}

Fonte: Pesquisa dos Autores (2018).

Ao observar a tabela (10), vemos que não houve grande variação em relação ao número de trabalhos publicados. Nos anos de 2013, 2015 e 2016 a quantidade de trabalhos é a mesma. Podemos identificar o aumento destes números apenas em 2017, quando houve a publicação de 4 (quatro) trabalhos. Os resultados desta pesquisa apresentam uma baixa variação ano a ano.

Ainda sobre esta temática, é importante salientar a importância da tecnologia, enquanto aliada à área da educação. Tanto nas zonas urbanas quanto nas rurais a escola deve se manter atualizada e servir como centro de referência não somente para o aprendizado, mas também para a pesquisa. Neste sentido, Pontuschka (2012, p. 95) diz que “... persiste ainda a ideia de que o professor da escola básica não necessita pesquisar. Tal posição tem reforçado uma concepção de professor como transmissor ou repassador de informação, mero usuário do produto do conhecimento científico". Isto é um paradigma que deve ser superado, evidenciando e reforçando o papel do docente enquanto pesquisador.

\section{Considerações}

O mapeamento destes dados foi importante para obter um panorama geral das produções científicas brasileiras em língua portuguesa, que abordam as temáticas da Tecnologia e da Educação do Campo, dentro da biblioteca digital do SciELO. A partir deste trabalho, começamos a identificar em quais campos a pesquisa esta mais avançada em relação à produção científica e, onde o número de trabalhos encontrados é menor, o que pode vir a atrair novas pesquisas e publicações. Notamos que as temáticas da Educação do Campo e da tecnologia são tendências atuais, e que podem abrir caminhos para novas pesquisas.

É interessante destacar que, a partir dos resultados filtrados por idioma, podemos detectar que a produção nacional não se restringe ao idioma português, pois observamos uma diminuição considerável, ao aplicarmos este filtro. 
Com base nos dados explicitados no mapeamento, que se referem aos resultados da produção científica brasileira e no idioma português, com a temática Tecnologia na Educação, podemos concluir que houve um aumento na publicação de artigos relacionados a esta temática. $\mathrm{O}$ mesmo pode ser observado em relação à temática Educação do Campo. Ambas mostraram um aumento no número de resultados obtidos, quando filtrados pelos últimos cinco anos e comparados aos resultados totais recuperados.

Quando passamos a focalizar na temática da Tecnologia na Educação do Campo, encontramos números bem distintos em comparação aos resultados recuperados quando buscamos pelas palavras-chave "Tecnologia na Educação" e "Educação do Campo" separadamente. Os artigos referenciados a este tema publicados no nosso país e em língua portuguesa apresentam números relativamente baixos, como podemos observar ao comparar os dados das tabelas. Este fato pode indicar uma provável carência de pesquisadores nesta área, a qual pode justificar-se dentre inúmeros motivos como: a falta de investimentos, carência de políticas públicas dedicadas à pesquisa, ou até mesmo, pouco interesse em levar temas como a tecnologia para dentro das escolas do campo.

\section{Referências}

Carlos, A. F. (2007). Seria o Brasil "menos urbano do que se calcula"? In Carlos, A. F. (Org.). O espaço urbano: novos escritos sobre a cidade (pp. 129-136). São Paulo, SP: Contexto.

Ferreira, A. B. H. (1999). Novo Aurélio Século XXI: o dicionário da língua portuguesa. Rio de Janeiro: Nova Fronteira.

Fischer, R. M. B. (2006). Televisão \& Educação: fruir e pensar a TV. Belo Horizonte, MG: Autêntica.

Fonseca, J. S. (2002). Metodologia da pesquisa científica. Fortaleza, CE: UEC.

Gil, A. C. (2017). Como elaborar projetos de pesquisa. São Paulo, SP: Atlas.

IBGE. (2010). Censo Demográfico. Recuperado de: http://www.ibge.gov.br

Kenski, V. M. (2015). Educação $e$ tecnologias: o novo ritmo da informação. Campinas, SP: Papirus.

Libâneo, J. C. (2007). A escola com que sonhamos é aquela que assegura a todos a formação cultural e científica para a vida pessoal, profissional e cidadã. In Costa, $\mathrm{M}$. V. (Org.). A escola tem futuro? (pp. 2350). Rio de Janeiro, RJ: Lamparina.

Minayo, M. C. (2012). $O$ desafio do conhecimento: pesquisa qualitativa em saúde. São Paulo, SP: Hucitec.

Minayo, M. C. S., \& Minayo-Goméz, C. (2003). Difíceis e possíveis relações entre métodos quantitativos e qualitativos nos estudos de problemas de saúde. In Goldenberg, P., Marsiglia, R. M. G., \& Gomes, M. H. A. (Orgs.). O clássico e o novo: tendências, objetos e abordagens em ciências sociais e saúde (pp. 117-142). Rio de Janeiro, RJ: Fiocruz. 
Goldenberg, S., Castro, R. C. F., \& Azevedo, F. R. M. (2007). Interpretação dos dados estatísticos da SciELO (Scientific Eletronic Library Online). Acta Cir. Bras. 22(1), 1-7. DOI: http://dx.doi.org/10.1590/S0102$\underline{86502007000100001}$

Polit, D. F., Beck, C. T., \& Hungler, B. P. (2011). Fundamentos de pesquisa em enfermagem: métodos, avaliação e utilização. Porto Alegre, RS: Artmed.

Pontuschka, N. N. (2012). Para ensinar e aprender Geografia. São Paulo, SP: Cortez.

Saviani, D. (2005). Pedagogia Históricocrítica: Primeiras aproximações. Campinas, SP: Autores Associados.

Vergueiro, W. (2010). Seleção de materiais de informação. Brasília: Brinquet de Lemos.

Recebido em: 08/12/2017

Aprovado em: 30/01/2018

Publicado em: 06/04/2018

\section{ORCID}

\author{
Vagner Viera de Souza \\ http://orcid.org/0000-0001-6667-222X \\ Elaine Corrêa Pereira \\ iD http://orcid.org/0000-0002-3779-1403 \\ Celiane Costa Machado \\ iD http://orcid.org/0000-0003-0685-8078
}

Declaramos que os autores foram responsáveis pela elaboração, análise e interpretação dos dados; escrita e revisão do conteúdo do manuscrito. Os autores também foram responsáveis pela aprovação da versão final a ser publicada

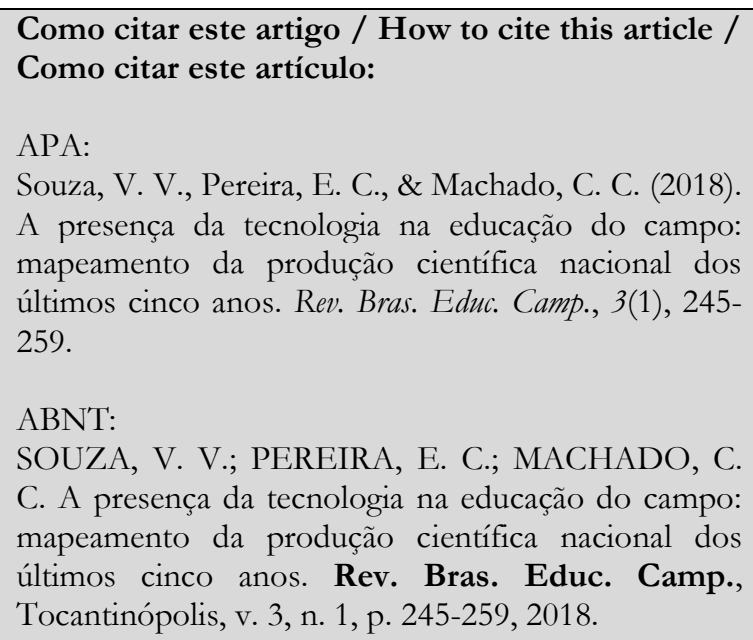

